\title{
DEGRADATION PHASE OF APOPTOSIS DURING THE EARLY STAGES OF HUMAN METANEPHROS DEVELOPMENT
}

\author{
Filip Wagner, Běla Erdösová, Dana Kylarová
}

\author{
Department of Histology and Embryology, Faculty of Medicine, Palacký University, Olomouc, Czech Republic \\ e-mail:wagner9x@tunw.upol.cz
}

Received: September 20, 2004

Keywords: Apoptosis/Human nephrogenesis/Metanephros/Kidney/Macrophage/CD64

\begin{abstract}
Apoptosis as a vital process is necessary for human intrauterine development. Not only the induction and course of apoptosis, but engulfment of the apoptotic cells (bodies) were the centre of our interest. Macrophages were detected in the early stages of human intrauterine development and the role of macrophages in the clearance of apoptotic cells in the early stages of human metanephros development was confirmed.
\end{abstract}

\section{INTRODUCTION}

The most frequent type of programmed cell death - apoptosis - is the focus of numerous scientists worldwide. It is a vital process, essential (with proliferation and differentiation) for human intrauterine development. Morphogenesis and apoptosis are based on genetic mechanism with intra- and extra- cellular stimulation. Three phases of apoptosis - initiation, execution and degradation - have been described. Typical morphological manifestation is a condensation of cytoplasm and nucleus, DNA degradation (fragmentation) and formation of membrane bound apoptotic bodies.

During the development of the human urinary system we distinguish two types of apoptosis - fast (critical) and slow (trickle-like), and three stages of development - pronephros, mesonephros and metanephros. The third stage - metanephros - is known as the definitive kidney and develops from the $5^{\text {th }}$ week of human intrauterine development (IUD). There are two major components of metanephros - nephric duct and metanephrogenic mesenchyme. From the nephric duct the ureteric bud grows and enters the metanephrogenic mesenchyme and activates condensation and differentiation of the metanephrogenic mesenchyme to the nephrons.

We focussed on the degradation phase of apoptosis especially in early stages of human metanephros development. The degradation phase of apoptosis is characterized by the phagocytosis of apoptotic bodies (apoptotic cells). Two types of phagocytes participate in the cleaning up of apoptotic bodies - professional (macrophage) and non-professional (for example immature fibroblasts and neighbouring epithelial cells). We studied the role of professional and non-professional phagocytes in clearing apoptotic bodies. The part of macrophages and non-professional phagocytes in apoptotic body cleaning changes during development, but there is a main role of macrophages. Exposing specific molecules - phosphatidylserine and vitronectin - on an external part of cytoplasmic membrane is an initial step in phagocytosis. The inflammatory reaction is absent - in contrast to necrosis.

\section{MATERIAL AND METHODS}

We used 8 histologically normal kidneys (collecting from embryos and foetuses ranging from $6^{\text {th }}$ to $12^{\text {th }}$ week of IUD). The tissues were processed by routine paraffin technique.

The first step was the detection of macrophages by a standard indirect three-step immunohistochemical method. We used mouse monoclonal macrophage antibody Ab-1 (Macrophage Marker, Oncogene), goat polyclonal antibody CD64 (N-19, Santa Cruz Biotechnology, Inc.) and mouse monoclonal antibody MMP9 - Matrix Metalloproteinase 9 (NCL-MMP9-439, Novocastra Lab.). Ab-1 was generated by immunizing mice with human macrophage membrane; CD64 is a specific surface glycoprotein receptor $(\mathrm{Fc} \gamma \mathrm{RI})$ constitutively expressed on monocytes and macrophages.

For the detection of apoptotic cells (apoptotic bodies), TUNEL (TdT-mediated dUTP nick end labelling method) was applied.

In the second step we used a double-staining technique to detect macrophages and apoptotic cells (bodies) in the same section and macrophage with two antibodies in the same section. We used this method to collocate macrophages and apoptotic bodies and to confirm the specifity of the macrophage antibodies. We used the TUNEL technique in combination with each single marker (TU/Ab-1, TU/CD64 and TU/MMP9) and all combination of two macrophage antibodies (Ab-1/CD64, Ab-1/MMP9 and CD64/MMP9).

The slides were observed by light microscope Olympus. 


\section{RESULTS}

Ab-1 and CD64 positive macrophage were detected prom the $6^{\text {th }}$ week of IUD. Positive cells in this age were found only sporadically but in older embryos and foetuses the quantity of positive cells raise, we detected small groups of positive cells.

MMP9 positive macrophages were present from the $8^{\text {th }}$ week of IUD, but they were not found in any other ages. MMP+ cells appear sporadically.

The apoptotic cells (bodies) were detected in all sections. We detected macrophages that engulf apoptotic bodies unambiguously in the $10^{\text {th }}$ week of IUD. Collocation of apoptotic bodies and macrophage markers was demonstrable in all three cases (TU/Ab-1, TU/CD64 and TU/MMP9)

The detection of macrophage with two antibodies on one slide (double-staining technique) was not convincing and the result was similar to detection of one macrophage marker.

\section{CONCLUSIONS AND DISCUSSION}

We detected macrophages of monocytic origin in early phases ( $6^{\text {th }}$ week of IUD) of human metanephros development and their participation in the clearance of apoptotic bodies. The presence of macrophages does not exclude participation of non-professional phagocytes.
The reliability of MMP9 as a macrophage marker is questionable, because it can be synthetized by mesenchymal cells as well and regulation of the expression of this antigen is very complicated.

\section{ACKNOWLEDGEMENT}

This work was supported by grants MŠMT 15100001.

\section{REFERENCES}

1. Brodbeck S, Englert C. (2004) Genetic determination of nephrogenesis: the Pax/Eya/Six gene network. Pediatr Nephrol 19, 249-255.

2. Erdösová B, Hlávková L, Procházková J, Lichnovský V. (2002) Part of CD68+ macrophages in the clearance of apoptotic bodies in human metanephros. Biomed. Papers 146, 41-45.

3. Gregory DC, Devitt A. (2004) The macrophage and the apoptotic cell: an innate immune interaction viewed simplistically? Immuno$\log 113,1-14$.

4. Grimsley C, Ravichandran KS. (2003) Cues for apoptotic cell engulfment: eat-me, don't eat-me and come-get-me signals. Trends in Cell Biology 13, 648-656.

5. Lockshin RA, Osborne B, Zakeri Z. (2000) Cell death in the third millennium. Cell Death and Differentiation 7, 2-7.

6. Wagner F, Erdösová B, Procházková J. (2003) The detection of phagocytes involved in executional phase of apoptosis in human metanephros. Biomed Papers 147, 243. 